\title{
O discurso sobre a precariedade em Luiz Ruffato e Arlindo Gonçalves José Leonardo Tonus ${ }^{1}$
}

Este trabalho visa analisar o lugar e o papel do insignificante nos romances Eles eram muitos cavalos, de Luiz Ruffato, e Desonrados e outros contos, de Arlindo Gonçalves. Em outras palavras, tratar-se-á, aqui, de observar como se articula nesses romances a discussão em torno da representação da pobreza e, mais particularmente, acerca da emergência de dispositivos paisagísticos no discurso sobre a precariedade. Tanto no universo plástico de Luiz Ruffato como na urbanidade polifônica de Arlindo Gonçalves, a paisagem urbana ocupa um lugar central na reflexão sobre a degradação social. Esta, no entanto, não se restringe ao registro nostálgico e melancólico de um mundo em ruínas. Em ambos os romances, as ruínas urbanas, sob a forma de escombros, constituem tanto o elemento desencadeador do processo de criação artística como o do seu fracasso.

Essa tensão se manifesta por uma percepção retalhada do mundo urbano: um conjunto de elementos estilhaçados e desprovidos de seus ouropéis sublinhando a nossa relação defasada com o território do alter. O inventário, a catalogação e a encenação desses objetos adquirem uma significação particular nos romances estudados. Tais procedimentos permitem que a voz autoral isole o elemento insignificante de seu entorno e passe a interrogá-lo sobre suas relações com o espaço urbano (Durante, 2004, p. 156). Em Arlindo Gonçalves e em Luiz Ruffato, as vozes autorais, próximas da atitude do dom, acolhem para dentro do espaço diegético o detrito, o residual e o objeto descaído. Em suma, o lixo adquire nesses romances um estatuto de alteridade precisa, que, pontualmente e mediante dispositivos paisagísticos, traduz um desvinculamento entre o sujeito, o objeto e a sociedade que se servia deles.

\section{Paisagens impossíveis}

Toda paisagem implica a existência de um ponto de vista em função do qual se estabelece a relação entre o sujeito, o entorno e sua representação. Em outras palavras, para que haja paisagem, são necessários um espaço, um corpo visível e um observador que, por meio dos mecanismos

${ }^{1}$ Doutor em estudos lusófonos. Professor da Université Paris-Sorbonne, Paris, França. E-mail: leotonusbr@hotmail.com. 
de extração, subtração, enquadramento e recomposição, transformam o "país em paisagem". Observar um pedaço de terreno com tudo o que nele existe, enquanto paisagem, requer reconsiderá-lo como uma delimitação e uma unidade arrancadas do espaço natural (Simmel, 1988, p. 233). A paisagem instaura, desse modo, uma relação com o fragmento, com o conjunto do que é oriundo e com o estado afetivo do observador que, ao contemplá-la, fabrica imagens, deslocando acentos, agrupando ou reagrupando elementos díspares. Para o filósofo Georg Simmel, esses procedimentos revelam a tragédia que vive a cultura ocidental moderna, pois, segundo ele, comprovam a separação definitiva entre o homem e a natureza, ou seja, a impossibilidade de apreensão do real em sua totalidade. Para Simmel, o desenvolvimento urbano só teria acentuado este processo, uma vez que o estilhaçamento da percepção espacial constitui um dos seus principais alicerces. Tais conclusões são, igualmente, compartilhadas pela geógrafa Françoise Choay, para quem a situação urbana atual é resultado de uma profunda transformação das cidades que, a partir do século XIX, desfizeram-se dos laços de solidariedade existentes desde a civilização romana. Segundo a geógrafa:

[No universo urbano] a interação entre os indivíduos é, doravante, multiplicada e, ao mesmo tempo, deslocalizada. O pertencimento às comunidades com interesses diversos já não se apoia nem na proximidade nem na densidade demográfica local. Transportes e telecomunicações nos colocam em relações cada vez mais numerosas e diferentes, [...] em implantações espaciais que já não coincidem nem representam estabilidade ou duração (Choay, 2007, p. 33, tradução nossa).

Ora, se, atualmente, o urbano, com suas redes marcadas pela preeminência das métricas topológicas, domina a cidade e a sua continuidade territorial, ele não as substitui. Contrariamente ao que um bom número de estudiosos afirma, cidade e mundo urbano não formam entidades antinômicas. Ambas descrevem relações de contiguidade, uma vez que a cidade ainda se apresenta como uma fração do urbano. A permanência residual de certos "geotipos" históricos, centrais e periféricos fortalece os laços entre estas duas realidades:

Do mesmo modo que o campo constitua o centro de um espaço, de uma sociedade e de uma civilização rural compreendendo cidades; o espaço, a sociedade e a civilização urbanas, que incluem diversas figuras do urbano, permanecem articulados em torno da cidade propriamente dita (Levy, 2003, p. 40, tradução nossa). 
No âmbito dos estudos literários, as distinções entre cidade e mundo urbano continuam, no entanto, ancoradas em noções antinômicas, que tendem a pensar essas realidades de maneira antitética: por um lado, a cidade com sua visão totalizante de um espaço fixo; por outro lado, o urbano, enquanto manifestação de um olhar inquieto, descontínuo e desprovido de unidade. Essa oposição redutora revela-se, igualmente, na concepção do termo "paisagem urbana", que, para o crítico Alain Mons (2007), constitui verdadeiro nonsense. O oximoro a partir do qual o termo foi forjado prova, segundo o crítico, a impossibilidade de acomodar numa mesma base nocional dois elementos irredutíveis: o natural da paisagem e o artifício do urbano. Se levarmos em conta que os oximoros, na concepção dos retóricos, não constituem figuras antitéticas nem antilógicas, uma possível aproximação entre os dois elementos parece-nos plausível. Como já afirmava Horácio em sua symphonia discors, os elementos antinômicos permitem também atingir a verdade. A justaposição de elementos aparentemente contraditórios abre as portas a discordantes harmonias que vêm a caracterizar as relações paradoxais da paisagem urbana: relações contrárias a uma doxa e desencadeadoras do processo de criação.

\section{O livro instalação}

O projeto do romance Eles eram muitos cavalos nasce, segundo depoimento de Luiz Ruffato, no final da década de 1990, após a constatação, pelo escritor, da crise de representação na ficção brasileira contemporânea. Nessa altura, Ruffato posicionava-se contra um certo conformismo intelectual, artístico e político, que, segundo ele, caracterizava aquela década. O projeto de Eles eram muitos cavalos se inscreve no desejo de romper com os códigos miméticos tradicionais de representação do real e buscar formas narrativas inovadoras. Com esse projeto, Ruffato visava estabelecer um compromisso entre engajamento estético, ético e político.

Contudo, suas primeiras interrogações conduzem-no a um impasse: como falar do precário e representar a precariedade social a partir de ferramentas poético-estéticas gastas? Para o autor, o discurso sobre o "precário" exigiria uma nova postura estética e novos instrumentos, que se situassem, também, no âmbito da precariedade. Em outras palavras, Ruffato buscava práticas discursivas cuja instabilidade e fragilidade pudessem não somente traduzir o real, mas, sobretudo, evidenciá-lo em sua forma mais espectral.

A partir de fevereiro de 2000, passei a estudar com afinco essa questão [a desagregação da sociedade] e, um dia, tive uma iluminação: só 
José Leonardo Tonus

poderia falar do precário precariamente. Então, lembrei-me de uma instalação de artes plásticas, possivelmente da Bienal Internacional de Artes de São Paulo de 1996 (de cujo artista e de cuja obra, infelizmente, não me lembro o nome e o título), que seguramente foi o mote de todo o trabalho posterior. O artista passou alguns dias recolhendo calçados usados e esquecidos nas ruas de São Paulo (seja, imagino eu, porque já não serviam por serem velhos, por terem sido esquecidos, por terem pertencido a alguém que tivesse sido atropelado ou porque seu dono, bêbado, abandonou-o na sarjeta). Eram centenas de calçados masculinos e femininos, de adultos e de crianças, tênis e sapatos, chinelos-de-dedo e pantufas, botas e sandálias, sapatinhos de crochê e coturnos. Caoticamente amontoados a um canto, ali, permaneceram, estáticos, aguardando que um olhar dali extraísse algo (Ruffato, 2008).

O projeto do livro toma corpo durante uma visita efetuada por Ruffato à Bienal de Artes de São Paulo de 1996, quando ele se depara com uma instalação do artista amazonense Roberto Evangelista, intitulada "Ritos de passagem". Concebida mediante os princípios da artialisation, segundo os critérios definidos pelo critico francês Alain Roger, "Ritos de passagem" se apresenta como uma instalação paisagística que obedece aos critérios básicos de seleção, extração e ressemantização de objetos provenientes de um espaço "natural". Na instalação, esses "objetos" tornam-se o emblema do estado de precariedade, de fragmentação e desagregação em que se encontra o sujeito oriundo do universo urbano.

A instalação de Roberto Evangelista compunha-se de mais de dois mil pares de sapatos usados, de milhares de caixas de sapato vazias e de pedras portuguesas oriundas das calçadas de Manaus. Os sapatos usados teriam por objetivo evocar os vestígios da sociedade brasileira contemporânea. As pedras portuguesas situariam o olhar do espectador no passado histórico do Brasil levando-o a se interrogar sobre os processos de aculturação e transplantação cultural o país teria vivenciado. Quanto às caixas de sapato vazias, elas aludiriam, pela ausência de seu conteúdo e dos bens de troca (os sapatos), o desgaste da sociedade capitalista e consumista. Para além de uma visão espectral da história brasileira, Ruffato vê nessa instalação e nos mecanismos paisagísticos aqui abarcados uma maneira de representar a precariedade social brasileira que ele tentará, por sua vez, implementar em seu romance. "Não sei qual tenha sido a intenção do artista, mas a minha leitura foi essa: cada um daqueles calçados era a história, conformada pelos pés que os usaram, impregnada pela sujidade dos caminhos percorrido" (Ruffato, 2008). 
Ruffato percorre durante mais de três meses as ruas da capital paulista em busca de objetos suscetíveis de evocar o estado de desagregação do universo urbano. A pé, de carro, de táxi, de metrô, de trem ou de ônibus, ele visita favelas, hospitais, estações de trem, supermercados e cemitérios. Ele participa de cultos evangélicos, assiste a missas, frequenta academias de boxe e estádios de futebol. Ele afirma, igualmente, ter visitado amigos e, em suas casas, anotado as listas de seus pertences ou os títulos dos livros das prateleiras de suas bibliotecas. Finalmente, em 9 maio de 2000, Ruffato compra todos os jornais e revistas publicados naquele dia em São Paulo e coleta todos os objetos encontrados no caminho para a banca de jornal: fragmentos de preces, menus de restaurantes, folhetos publicitários. Em suma, ele inscreve seu projeto na estratégia do colecionador-arquivista e dos mecanismos paisagísticos, como se, por estes, a voz autoral pudesse apreender de maneira falsamente aleatória a natureza em sua totalidade tornando-se, deste modo, o depositário de uma alteridade esquecida ou ocultada. "De fevereiro a maio passeei pelas ruas, não anotando nada, mas deixando que as ruas, com seus cheiros, suas vozes, suas cores, seus esbarrões, marcassem meu corpo e que ele fosse o fiel depositário de tudo que se passava à minha volta" (Ruffato, 2008).

É somente após a coleta que Luiz Ruffato dá início à redação do romance, nomeadamente após juntar, classificar e transformar o material recolhido. Durante mais de um mês, ele toma notas, estabelece esquemas, recorta e cola os objetos encontrados. Realiza uma bricolagem artística, por meio da qual, paulatinamente, priva o objeto residual de sua função original, conferindo-lhe um estatuto espectral capaz de evocar a civilização que os gerou. É a partir desse espaço agônico que nasce a redação do romance Eles eram muitos cavalos. Ruffato visa, assim, atingir a memória de uma experiência que o leva a abandonar o material coletado e centrar-se nas cicatrizes que esta teria deixado em seu corpo. Através desse procedimento, o escritor busca anular as relações miméticas entre o texto e o seu entorno, instaurando uma lógica narrativa apoiada exclusivamente no precário. Se a memória, as lembranças ou as impressões de sua aventura devem figurar no texto a ser escrito, o são pelo viés do apagamento e do esquecimento.

Findo o mês, levava de volta para São Paulo três pastas de plástico com inúmeras folhas de papel-sulfite e uma pergunta: o que fazer agora? Ali está o livro de ficção que eu queria ou poderia escrever? Ao cabo de alguns dias, a resposta surgiu, transparente: não, ali ainda não havia arte... Então, prontamente, deixei de lado as pastas de plástico e me abandonei totalmente à escrita ficcional, tentando 
José Leonardo Tonus

trazer para dentro do romance todas as linguagens de que meu corpo havia se apercebido naqueles meses: cadernos escolares, emissões radiofônicas, diálogos apenas entreouvidos, crônica policial, contos tradicionais, poemas, notícias de jornais, classificados, descrições insípidas, recursos de alta tecnologia (mensagens de telefone, de internet), discursos religiosos, colagens, música (do clássico ao rap), cartas... tudo: cinema, literatura, artes plásticas, música, teatro... uma "instalação literária", enfim (Ruffato, 2008).

Eles eram muitos cavalos surpreende-nos pela importância que o autor confere aos objetos residuais e aos elementos insignificantes de nossa sociedade. Com sua formas múltiplas, seu amontoado de vozes, discursos e pontos de vista anônimos, Ruffato nos proporciona uma visão heterogênea do universo urbano que, a partir do espectro, instaura um possível diálogo com as margens. No romance, São Paulo, cidade dos escombros, torna-se uma paisagem humana palimpséstica, de onde emerge uma alteridade "despetrificada", que, no entanto, continua a fugir do nosso olhar. Nesse espaço agônico, o leitor-observador caminha com dificuldade, assistindo, por vezes, de maneira impassível, aos processos de decomposição social. Seu percurso termina nas últimas páginas do livro que, à maneira de uma cortina de teatro, anuncia o fim de um espetáculo. Um espetáculo precário sobre uma sociedade que, também precária, situa-se num paisagem esvaziada de sua substância: páginas negras de um romance.

\section{A carne da paisagem}

Publicado em 2004, Desonrados e outros contos, de Arlindo Gonçalves, inscreve-se num projeto romanesco mais amplo, composto de três obras, em que se alternam narrativas breves e imagens fotográficas ${ }^{2}$. Nesse livro, o autor se serve de uma técnica de escrita semelhante à de outros romances, uma vez que organiza o texto a partir do entrecruzamento de narrativas breves, autônomas e próximos da estrutura do conto. As histórias inseridas no romance respeitam as regras da escrita contística tradicional, limitando suas intrigas a uma personagem, a espaços, a temporalidades e a ações restritas.

Desonrados e outros contos evoca a trajetória de uma dezena de personagens solitárias. Todas coabitam o espaço caótico da cidade de São Paulo,

\footnotetext{
${ }^{2}$ Esse projeto compreende os romances Dores perdidas (São Paulo, Edições Inteligentes, 2004), Desonrados e outros contos (São Paulo, Marco Zero, 2005) e Desacelerada mecânica cotidiana (São Paulo, Horizonte, 2008).
}

52 est. lit. bras. contemp., Brasília, n. 41, p. 47-59, jan./jun. 2013 
em que não param de se cruzar. Tais encontros não alteram em nada seus destinos marcados pelo sofrimento. Pelo contrário, o percurso individual e solitário de cada uma desses personagens reforça o aspecto trágico de suas existências. Como atestam as imagens fotográficas presentes ao longo do romance, as personagens permanecem perdidas no espaço labiríntico da cidade.

Dispostas de maneira aleatória ao longo da obra, as imagens fotográficas ilustram a ação em curso e encenam a colisão entre o universo da metrópole moderna e o mundo da precariedade social. Os objetos e personagens aqui representados desempenham um papel fulcral nesse processo. Através deles, estabelecem-se redes metafóricas, metonímicas e analógicas que asseguram a emergência de dispositivos paisagísticos, interrogando-nos acerca das relações entre sujeito e objeto num contexto marcado pela precariedade social. Todas as imagens fotográficas, de fato, tendem a privilegiar o insignificante como elemento estético. Elas registram, expõem e encenam o lixo de nossa sociedade consumista. As sobras, os objetos abandonados ou esquecidos, os resíduos e restos humanos surgem nas narrativas como elementos de uma paisagem que transforma o espaço diegético num locus privilegiado de enunciação sobre as margens. Através dessas imagens, o autor não busca somente dar voz aos assim chamados afásicos sociais. Trata-se aqui, antes, de instaurar uma relação efêmera com o alter a partir de uma base espacial que permita ao fotógrafo-narrador evitar as armadilhas da espetacularização das margens. No lixo e pelo lixo, a voz autoral aspira a um espaço intersticial que, desconfortável, possa confrontá-lo, bem como seu observador-leitor, com os sintomas da desagregação da sociedade urbana. O lixo, desprovido de seu aspecto esplendoroso, torna-se esse medium efêmero por meio do qual uma alteridade em fiapos se manifesta. Essa questão constitui o fio condutor das três imagens selecionadas para esta análise.

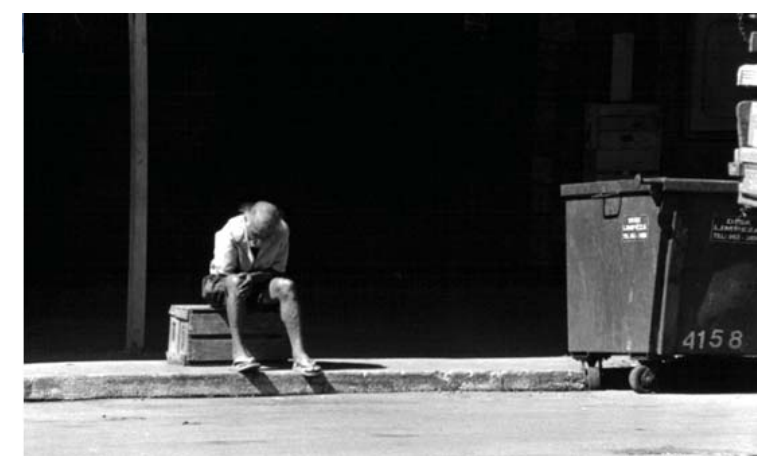

Figura 1. Mendigo. Fonte: Gonçalves (2004, p. 50-51).

est. lit. bras. contemp., Brasília, n. 41, p. 47-59, jan./jun. 201353 
José Leonardo Tonus

A figura 1 representa um mendigo perdido em seus pensamentos e sentado num caixote de frutas colocado na calçada de uma cidade. Uma luz ofuscante ilumina a cena e confere ao espaço urbano uma atmosfera mágica fora do tempo. No prolongamento das linhas horizontais sugeridas pela sarjeta da calçada onde se encontra o mendigo, vê-se, num primeiro plano, um contêiner de lixo cortado ao meio pela tomada fotográfica. Suas rodas, rígidas e voltadas para fora, evocam o fim de um deslocamento que respondem, na fotografia, ao movimento efetuado pelo mendigo. Seu pé direito está levemente suspenso, ao passo que o esquerdo, colocado à frente da personagem, guia o olhar do observador, novamente, em direção ao primeiro plano, representado pelo contêiner de viés.

A disposição dos elementos que compõem a imagem, bem como a luz artificial que reina nela, acentuam o efeito de encenação. Elas criam um jogo ilusório conferindo ao contêiner um aspecto quase humano. A alça e o ferro do encaixe do tampo, ausente na imagem, aludem à forma de um rosto, cujo olhar penetrante (o prego do ferro de encaixe) atinge o observador situado no ponto externo à cena. $\mathrm{O}$ movimento deste olhar efetuado da direita para a esquerda exclui totalmente a presença do mendigo, que mantém seu rosto abaixado.

Realizada a partir da multiplicação de pontos de vista e das relações paradoxais do oximoro, a imagem fotográfica propõe uma leitura interessante acerca dos procedimentos de exclusão e de desumanização decorrentes do crescimento das grandes metrópoles. Por um lado, ela expõe a fragilidade do mendigo, cuja postura alude à posição de inferioridade que ocupa nas hierarquias sociais. Por outro lado, assinala, por meio da arrogância do contêiner, que domina a cena, os procedimentos de sujeição e "objetificação" a que as classes mais pobres são submetidas. Finalmente, ela testemunha o fracasso da dialética paisagística no contexto da contemporaneidade. A imagem fotográfica recontextualiza a figura do pensador de Rodin, que doravante, torna-se unicamente o emblema da submissão do homem às leis avassaladoras da natureza que ele já não pode mais controlar. 


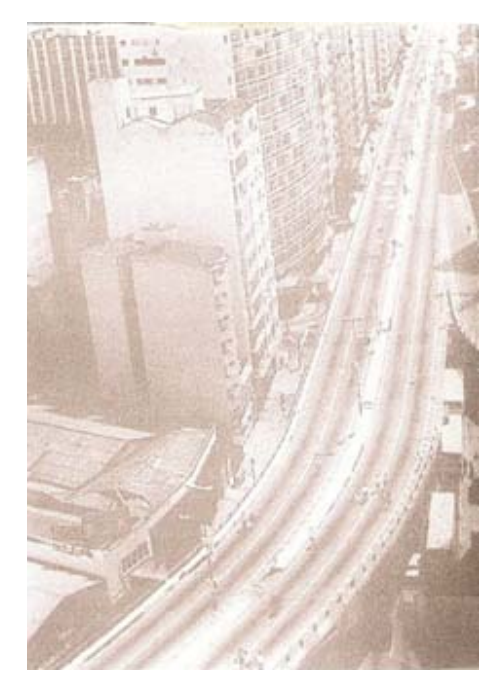

Figura 2. Viaduto do Minhocão - São Paulo. Fonte: Gonçalves (2004, p. 18).

O nonsense domina, igualmente, a segunda imagem fotográfica, que mostra uma vista parcial do viaduto do Minhocão em pleno centro nevrálgico da cidade de São Paulo. A imagem está inserida no primeiro texto do romance, quando um narrador onisciente evoca o despertar de um velho homem deficiente numa manhã de domingo. A personagem erguese com dificuldade e, de sua janela, observa a paisagem do Minhocão sem carros. Se a fotografia ilustra o texto, a narrativa, em contrapartida, confere à imagem fotográfica um estatuto de paisagem mediante um enquadramento instável. O velho homem mal consegue manter-se em suas muletas e seu olhar titubeante acentua o efeito de desequilíbrio que o ângulo em plongée da fotografia corrobora. A sensação de queda é imediata, como se a imagem propulsasse o leitor/observador para os abismos do mundo urbano, representado aqui pela figura do Minhocão. O desequilíbrio instaurado altera, igualmente, a percepção dos objetos que compõem essa fotografia absurda, em que o viaduto parece desprover-se da substância que o caracterizava. Os carros desapareceram e pedestres tomaram conta do espaço urbano implementando novas formas de habitabilidade e de ocupação clandestina. O desequilíbrio da cena repercute-se, finalmente, na representação do próprio viaduto. Suas pilastras sumiram e este, situado no nível da avenida, prolonga-se até o infinito numa horizontalidade vertiginosa. Sem escoras ou nenhum outro tipo de apoio, o Minhocão vacila e nosso olhar soçobra, como na terceira imagem aqui analisada. 


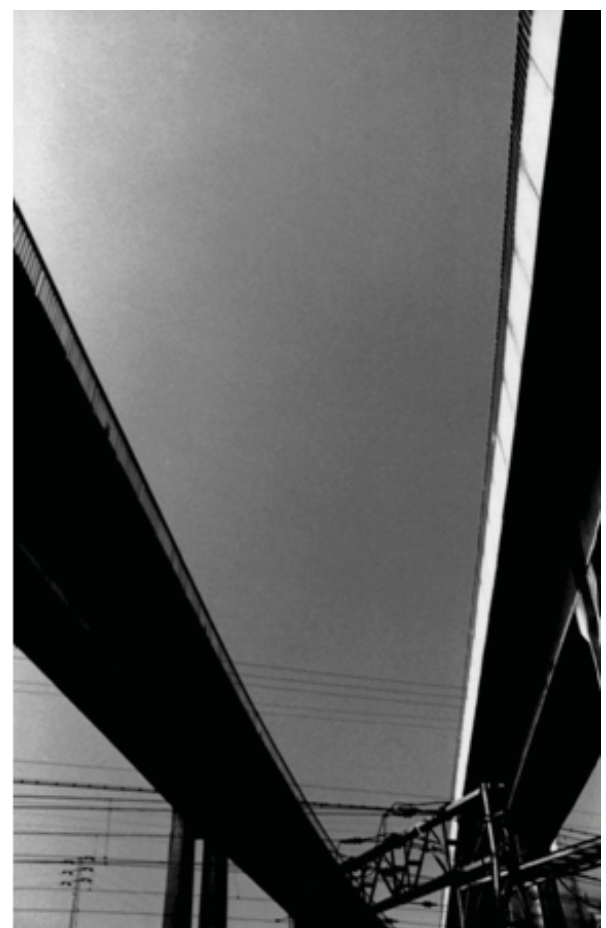

Figura 3. Viadutos São Paulo. Fonte: Gonçalves (2004, p. 41).

Realizada a partir de um ângulo em contra-plongée, esta fotografia produz uma sensação de vertigem sublinhada pelas pontes horizontais presentes. Para além de desempenharem o papel de pontos de fuga, elas acabam por instaurar um movimento contínuo, aspirando e expulsando o olhar do sujeito observador para dentro e para fora da paisagem que ele próprio criara. A imagem fotográfica vem, nesse sentido, comprovar a maneira como se estabelecem os dispositivos paisagísticos no texto: uma experiência onde sujeito observador e objeto observado permanecem inseparáveis. O objeto espacial é constituído pelo sujeito que, por sua vez, encontra-se englobado nele.

Mas, se a presença de um observador é indispensável para que haja paisagem, o que fazer quando ele integra um espaço em que já não há mais nada para se ver ou onde não se vê mais nada? Face ao insignificante, a imagem fotográfica paisagística deixa aqui de desempenhar seu papel de medium. Não somente ela já não produz sentido como conduz o sujeito à cegueira. 


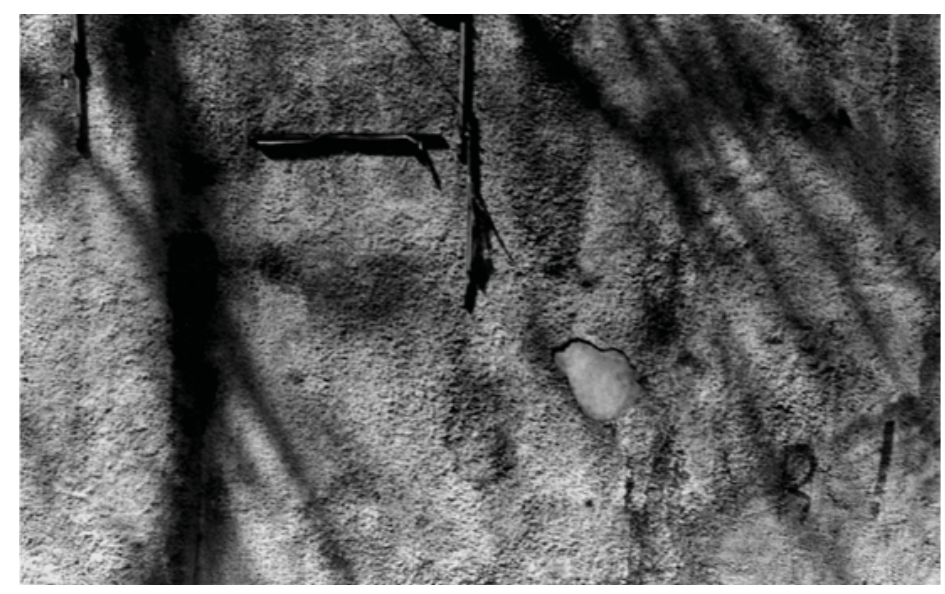

Figura 4. Muro. Fonte: Gonçalves (2004, p. 14-15).

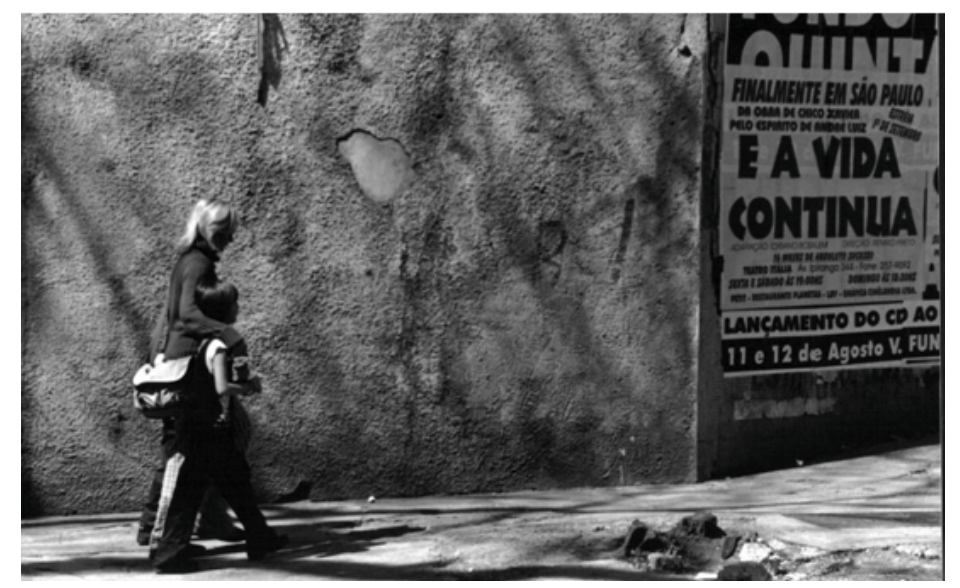

Figura 5. Muro com cartazes. Fonte: Gonçalves (2004, p. 25).

Esta questão constitui o tema central da figura 4, que se compõe de elementos díspares e informes dispostos sobre um fundo acinzentado, de onde se observa a presença de algumas manchas negras, sinais e letras apagados. A imagem apresenta também, na parte superior esquerda, um objeto cilíndrico de aspecto metálico. Sua liquidez contrasta com o elemento situado logo abaixo das letras, à direita, cuja nuances cinza-claro conferem-lhe um aspecto gosmento. Nada nos permite, no entanto, distinguir, de maneira precisa, a natureza dos objetos aqui representados. A própria imagem (restaurada algumas páginas adiante) é fruto de uma 
colagem e de uma distorção por ampliação do elemento fotografado (figura 5). Tal qual uma anamorfose fotográfica, essa imagem, inserida no paratexto do livro, apresenta-se como um paisagem-epígrafe, anunciando e comentando de maneira sugestiva o sentido da história que iremos ler: uma história composta de outras várias histórias (textuais e fotográficas), ao longo das quais, o sujeito enunciador expõe a precariedade social, como também se expõe enquanto palavra precária de uma paisagem que, igualmente precária, obscena e paradoxal, deve ser ocultada do nosso olhar.

Em Eles eram muitos cavalos, de Luiz Ruffato, e em Desonrados e outros contos, de Arlindo Gonçalves, a paisagem urbana inscreve-se frequentemente na lógica dos oximoros. Em ambos os textos, ela apresenta as relações paradoxais de que se compõe nosso cotidiano. O romance fotográfico de Arlindo Gonçalves e a instalação romanesca de Luiz Ruffato exibem, ao longo de suas narrativas, as possibilidades e os limites do diálogo com o alter. Por meio dos objetos residuais inadaptados ao consumo ou amputados de sua função social, eles testemunham como as palavras e as imagens já não verbalizam, nem mostram mais nada, exceto, talvez, a eterna precariedade do impulso da criação artística.

\section{Referências}

CHOAY, Françoise (2007). Le règne de l'urbain et la mort de la ville. In: DETHIER, J.; GUIHEUX, A. (dirs.). La ville, art et architecture en Europe, 1870-1993. Paris: Centre Pompidou.

GONÇALVES, Arlindo (2004). Desonrados e outros contos. São Paulo: Marco Zero. DURANTE, Daniel Castillho (2004). Les dépouilles de l'altérité. Montréal: XYZ. LEVY, Jacques (2003). Dictionnaire de géographie. Paris: Belin.

MONS, Alain (2007) Le paysage urbain comme chaos. Figures Photographiques. In: SANSON, Pascal (dir.). Le paysage urbain (représentations, significations, communication). Paris: L'Harmattan.

RUFFATO, Luiz (2000). Eles eram muitos cavalos. 3. ed. São Paulo: Boitempo. (2008). Depoimento oral ao autor.

SIMMEL, George (1988). Philosophie du paysage (1913). In: de la culture. Paris: Rivages. La tragédie

Recebido em maio 2012.

Aprovado em outubro 2012. 


\section{resumolabstract}

\section{O discurso sobre a precariedade em Luiz Ruffato e Arlindo Gonçalves}

José Leonardo Tonus

Este trabalho visa analisar a maneira como os dispositivos paisagísticos contribuem nos romances Eles eram muitos cavalos, de Luiz Ruffato, e Desonrados e outros contos, de Arlindo Gonçalves, à emergência de um discurso sobre o precário. Se a paisagem ocupa, nesses textos, um lugar fulcral na reflexão sobre a degradação social, ela não se limita ao registro nostálgico de um mundo em ruínas. Em ambos os romances, ela constitue tanto o elemento desencadeador do processo de criação artística como o do seu fracasso. À imagem de nossa percepção retalhada do universo urbano degradado, a paisagem assinala aqui a nossa relação defasada com o território do alter.

Palavras-chave: Luiz Ruffato, Arlindo Gonçalves, paisagem, precário, ruínas.

The discourse about precariousness in Luiz Ruffato and Arlindo Gonçalves José José Leonardo Tonus

This study aims to analyze how, in the novels Eles eram muitos cavalos by Luiz Ruffato and Desonrados e outros contos by Arlindo Gonçalves, the literary device of landscape contributes to the emergence of a discourse about precariousness. If the landscape occupies, in these texts, a central place in thinking about social degradation, it is not limited to a nostalgic record of a world in ruins. In both novels, the device of landcape contibutes both to the triggering element of artistic creation as much as its failure. Like our fragmented perception of a degraded urban universe, here the landscape indicates our relationship with the alter territory.

Keywords: Luiz Ruffato, Arlindo Gonçalves, landscape, precariousness, ruins. 